\title{
Painful Truth: The Need to Re-Center Chronic Pain on the Functional Role of Pain
}

\author{
Vivian Santiago \\ Department of Oral \& Maxillofacial Pathology, Radiology \& Medicine, New York University College of Dentistry, New York, NY, USA \\ Correspondence: Vivian Santiago, Email vs1555@nyu.edu
}

\begin{abstract}
Pain is undesirable, whether it is a symptom of mild or severe illness or instead indicates disorder in the nervous system's ability to perceive and process sensory information. Nonetheless, pain is part of the body's ability to defend itself and promote its own survival - this is its fundamental evolutionary function. This normal expression of pain is not limited to what is considered useful because it alerts us to the initiation of illness. It also applies to pain that continues when illness or noxious stimuli persist. However, the parameters of what is here termed functional pain are not fully understood and are seldom explicitly the focus of research. This paper posits that failure to appreciate the functional role of pain in research has had significant unintended consequences and may be contributing to inconsistent research findings. To that end, the paper describes the misclassification issue at the core of chronic pain research - whether a given pain reflects functional or pathological processes - and discusses research areas where reconsidering the functional role of pain may lead to advancements.
\end{abstract}

Keywords: pain dysfunction, pain disorder, pathology, construct validity

\section{Introduction}

The human body's ability to feel pain is part of its defense mechanisms for maintaining its integrity and protecting itself from harm, ${ }^{1,2}$ inherently within a biopsychosocial framework. ${ }^{3,4}$ However, by definition, ${ }^{5}$ all pain hurts; thus, justifiably, the motivation of most health research on pain is to stop the pain. Pain's aversive qualities make it difficult to remember its evolutionarily acquired function, particularly when it is persistent, recurrent or intractable. Nonetheless, even when a given manifestation of pain is chronic and reflects disordered sensory perception or processing, considering the functional role of pain generally is critical to understanding pain pathology, and how best to diagnose and treat. Moreover, given the complexity of the human body and its ability to feel pain as a means of preventing tissue damage and promoting healing, respecting the functional role of pain would help to minimize unnecessary or harmful interference with the body's inherently necessary defenses.

This manuscript calls for a re-centering of pain research on the functional role of pain. First, it describes how recentering will help clarify the fundamental misclassification issue in chronic pain research and practice-whether the manifested pain is a symptom of a systemic illness or injury, or if it instead reflects a disorder itself (Figure 1). A disorder of pain would imply pathology ${ }^{6}$ in the somatosensory and associated processes that bring about the ability to feel pain, while pain as a symptom of systemic illness or injury would reflect what is here termed functional pain (Table 1). Precision in operationalizing and distinguishing between these two research targets (functional vs pathological pain) would improve research case groups, thereby mitigating misclassification, and potentially lead to more conclusive study results necessary to advance our taxonomic systems and develop effective treatments. In turn, this will have significant implications for pain prevention, and for anticipating and avoiding unintended consequences. Second, the paper presents recommendations for research to better address the functional role of pain in efforts to advance chronic pain research (Table 2). The call for reconsideration of functional pain in research and of its potential benefit for well-being should not be misinterpreted as a call not to treat functional pain. On the contrary, the author hopes the re-centering of functional pain in chronic pain research will lead to better interventions to safely reduce all suffering. 


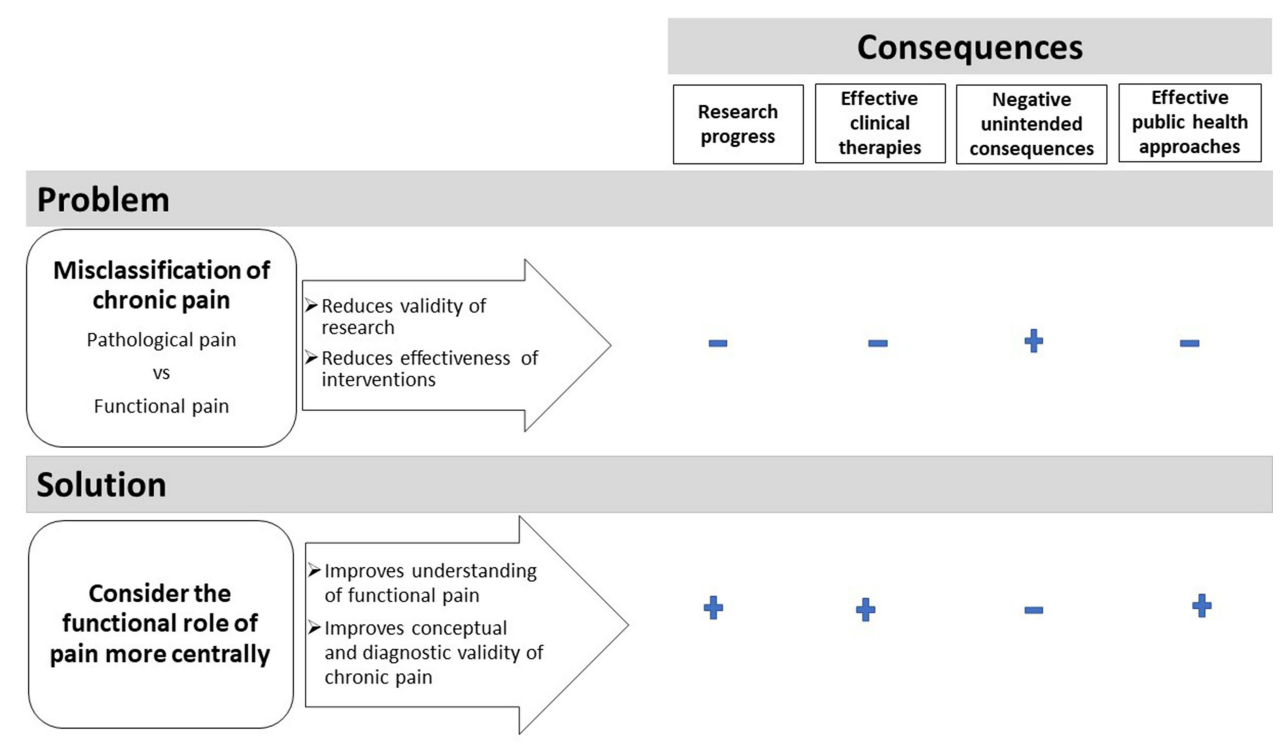

Figure I Overview of the main proposed problem, consequences and solution.

\section{What is the Functional Role of Pain?}

Simply, pain warns us of potential danger to tissue harm or to the presence of injury. This insult can be within or outside the nervous system, physical or chemical, visible or not. Although the characteristics of pain may differ, the role is still the same; pain is the body's alert system. ${ }^{2,6,7}$ Research on congenital insensitivity to pain demonstrates that the inability to feel pain is associated with increased injury, associated infection and a shorter lifespan. ${ }^{8}$

Of note, this manuscript focuses on "physical" pain consistent with the International Association for the Study of Pain (IASP) definition of pain ${ }^{5}$ (see Table 1), which includes an important emotional component. However, the focus will not be "psychological pain" itself, which is an equally important but distinct phenomenon",10 (eg, psychological pain as experienced in depression, not as the psychological features of physical pain which themselves may be associated with depression). Additionally, the use of "functional pain" here should not be confused with the term as used in neurology to apply to chronic pain conditions without clear, organic origin. ${ }^{11}$

The term functional pain is used here to describe pain that results from the human body's innate ability to protect itself, ie, the function of pain (Table 1). This is pain that is normal - pain that is a result of a functional somatosensory system. It is not to imply that any specific experience of pain needs to confer direct benefit to the individual from our Westernized, modern-day perspective in order for it to be normal. Rather, our somatosensory and associated systems (herein referred to as the "pain system" for brevity) evolved to function in a way that, in evolutionary terms, conferred a survival benefit via the ability to feel pain. When pain reflects these normal processes, then it is functional as is often implied in research on pain. ${ }^{2,7,12}$ However, current knowledge of the neurophysiological underpinnings of the role of pain is limited due to its complexity (see recommendation sections on evolutionary origins, systems approaches, and translation).

The simplest notion of pain is considered to result from nociception, which "begins when energy that produces or threatens to produce imminent injury (a noxious stimulus) is transduced into neural activity, leading to organized responses that defend the tissue under threat and aid in its repair". ${ }^{12}$ Yet, pain also manifests in a more complex manner once injury has occurred; this is inflammatory pain. ${ }^{2}$ Inflammatory pain is also considered to be adaptive, as it helps with healing ${ }^{2}$ by internally signaling the cascade of molecular healing mechanisms, mobilizing the individual to take care of the injury and allowing for social efforts to promote survival. ${ }^{12}$ Although nociception may have initiated this pain, the inflammatory process transforms the pain experience beyond nociceptive pain via neuroplastic changes ${ }^{2}$ and includes features like hyperalgesia and allodynia (see Table 1). These manifestations reflect pain in and around the injured area 
Table I Pain Terms and Related Definitions

\begin{tabular}{|c|c|}
\hline Term & Definition \\
\hline Pain & $\begin{array}{l}\text { "An unpleasant sensory and emotional experience associated with, or resembling that associated with, actual or } \\
\text { potential tissue damage". }\end{array}$ \\
\hline $\begin{array}{l}\text { Functional pain (as used in } \\
\text { this paper) }\end{array}$ & $\begin{array}{l}\text { Pain that reflects the evolutionarily adapted functional role of pain for survival. Pain may result from the normal } \\
\text { function of the nervous system in response to acute, diffused, localized, intermittent, chronic, systemic, internal } \\
\text { or external noxious stimuli of known or unknown origin. This pain reflects a healthy nervous system. }\end{array}$ \\
\hline $\begin{array}{l}\text { Pathological pain (as used in } \\
\text { this paper) }\end{array}$ & $\begin{array}{l}\text { Pain resulting from pathology or dysfunction of the nervous system's processes responsible for pain, ie of the } \\
\text { somatosensory and related systems of functional pain. In contrast to functional pain, pathological pain does not } \\
\text { reflect a healthy nervous system's pain response. }\end{array}$ \\
\hline Acute pain & $\begin{array}{l}\text { "Acute pain is awareness of noxious signaling from recently damaged tissue, complicated by sensitization in the } \\
\text { periphery and within the central nervous system (CNS)". }{ }^{44}\end{array}$ \\
\hline Chronic pain & "Chronic pain [is] defined as persistent or recurrent pain lasting longer than 3 months". ${ }^{3}$ \\
\hline Chronic primary pain & $\begin{array}{l}\text { "... pain in one or more anatomical regions that persists or recurs for longer than } 3 \text { months and is associated } \\
\text { with significant emotional distress or functional disability" and "that cannot be better accounted for by another } \\
\text { chronic pain condition". }{ }^{9,95}\end{array}$ \\
\hline Chronic secondary pain & $\begin{array}{l}\text { Pain condition "linked to other diseases as the underlying cause, for which pain may initially be regarded as } \\
\text { a symptom" and "relevant as a codiagnosis, when this symptom requires specific care for the patient". } 19\end{array}$ \\
\hline Nociception & "The neural process of encoding noxious stimuli". ${ }^{a}$ \\
\hline Hyperalgesia & "Increased pain from a stimulus that normally provokes pain". a \\
\hline Allodynia & "Pain due to a stimulus that does not normally provoke pain". \\
\hline Nociplastic pain & $\begin{array}{l}\text { "Pain that arises from altered nociception despite no clear evidence of actual or threatened tissue damage } \\
\text { causing the activation of peripheral nociceptors or evidence for disease or lesion of the somatosensory system } \\
\text { causing the pain". }\end{array}$ \\
\hline Neuropathic pain & "Pain caused by a lesion or disease of the somatosensory nervous system". \\
\hline $\begin{array}{l}\text { Disorder as harmful- } \\
\text { dysfunction }\end{array}$ & $\begin{array}{l}\text { Two conditions must be met: "(a) the condition causes some harm or deprivation of benefit to the person as } \\
\text { judged by the standards of the person's culture ..." and "(b) the condition results from the inability of some } \\
\text { internal mechanism to perform its natural function ... ", ie results from an "internal-dysfunction". b, } 88\end{array}$ \\
\hline
\end{tabular}

Notes: ${ }^{a}$ International Association for the Study of Pain (IASP) definitions. ${ }^{26}$ Refer to the website ${ }^{25}$ for updated notes on each definition. ${ }^{\mathrm{b}}$ See page 384 of Wakefield. ${ }^{88}$ Superscript numbers refer to cited source as listed in the References section.

(hyperalgesia) or pain sensitivity to usually non-painful stimuli (allodynia), which go beyond a direct proportional effect of injury, reflecting the nervous system's ability to modify bodily perceptions in response to injury. This, too, is a normal response expected to end once healing has occurred. Pain that persists beyond presumed healing time, on the other hand, is considered maladaptive or pathological pain.

\section{The Problem of Chronic Pain}

Persistent or chronic pain is of specific clinical concern given assumptions of its maladaptive nature. Attempts to define chronic pain continue to rest on duration of symptoms beyond normal tissue healing, ${ }^{5}$ under the assumption that 3 months ${ }^{13}$ is the adequate healing time. Pain experienced after this period is considered to have outlasted its functional purpose and assumed to reflect pathological states (Figure 2A). Although this approach is a useful start to establish taxonomic practice and promote research in light of incomplete knowledge, it has its limitations. In validly refining the construct of pathological pain, two main issues remain. First, it is not evident that 3 months is adequate time for healing for all conditions; therefore, some conditions classified as chronic pain may, in truth, be acute pain or subacute pain maintained by ongoing noxious stimuli (ie, functional pain) rather than pathological chronic pain (Figure 2B). For 
Table 2 Recommendations for Anchoring Pain Research on the Functional Role of Pain

\begin{tabular}{|c|c|c|}
\hline $\begin{array}{l}\text { Recommended Area of } \\
\text { Research }\end{array}$ & Key Topics Discussed & Potential Impact \\
\hline $\begin{array}{l}\text { Evolutionary understanding of } \\
\text { "functional pain" }\end{array}$ & $\begin{array}{l}\text { - Evolutionary theory and pain } \\
\text { - Research on pain experience across species } \\
\text { - What is functional pain and its characteristics? }\end{array}$ & $\begin{array}{l}\rightarrow \text { Improve conceptualization and measurement of } \\
\text { pain }\end{array}$ \\
\hline $\begin{array}{l}\text { Developmental research on } \\
\text { the functional role of pain }\end{array}$ & $\begin{array}{l}\text { - What fosters a healthy somatosensory system including the ability to feel } \\
\text { pain? } \\
\text { - Natural history of functional pain } \\
\text { - Changes in the ability to experience functional pain over the life-course }\end{array}$ & $\begin{aligned} \rightarrow & \text { Improve conceptualization and measurement of } \\
& \text { pain } \\
\rightarrow & \text { Reduce unintended consequences }\end{aligned}$ \\
\hline Potential benefits of pain & $\begin{array}{l}\text { - Potential unintended consequences of pain interventions } \\
\text { - Potential benefits of the ability to feel pain for health and well-being, and how } \\
\text { this might be leveraged to develop effective interventions }\end{array}$ & $\begin{array}{l}\rightarrow \text { Improve net benefit of interventions } \\
\rightarrow \text { Reduce unintended consequences }\end{array}$ \\
\hline Systems science approaches & $\begin{array}{l}\text { - Study of pain as a result of complex adaptive systems } \\
\text { - Whole person-centered research } \\
\text { - Biopsychosocial framework } \\
\text { - Evaluation of multimodal treatments }\end{array}$ & $\begin{array}{l}\rightarrow \text { Improved integrative understanding of pain } \\
\rightarrow \text { Reduce unintended consequences }\end{array}$ \\
\hline Translational considerations & $\begin{array}{l}\text { - Clarity of target constructs } \\
\text { - Models used (functional vs pathological pain) } \\
\text { - Causal inference } \\
\text { - Knowledge translation and integration } \\
\text { - Setting of research priorities }\end{array}$ & $\begin{array}{l}\rightarrow \text { Improve validity of research } \\
\rightarrow \text { Improve knowledge translation } \\
\rightarrow \text { Reduce time to therapeutic discovery } \\
\rightarrow \text { Reduce unintended consequences }\end{array}$ \\
\hline $\begin{array}{l}\text { Conceptual grounding of pain } \\
\text { as disorder }\end{array}$ & $\begin{array}{l}\text { - Validity of constructs } \\
\text { - Integration of research }\end{array}$ & $\begin{array}{l}\rightarrow \text { Improve conceptualization and measurement of } \\
\text { pain } \\
\rightarrow \text { Reduce unintended consequences }\end{array}$ \\
\hline $\begin{array}{l}\text { Ethical and epigenetic } \\
\text { considerations }\end{array}$ & $\begin{array}{l}\text { - Evolutionary function of pain is inherently wedded to the environment } \\
\text { (broadly defined) } \\
\text { - Defining diagnostic boundaries require ethical considerations } \\
\text { - Addressing pain also requires consideration of noxious stimuli in physical, } \\
\text { societal, work and interpersonal environments } \\
\text { - Potential long-term impacts of current practice and expectations around pain } \\
\text { should be considered } \\
\text { - Critical examination of how our societies are constructed to treat and care } \\
\text { for our bodies is warranted }\end{array}$ & $\begin{array}{l}\rightarrow \text { Improve public health and population health } \\
\text { approaches to pain } \\
\rightarrow \text { Reduce unintended consequences }\end{array}$ \\
\hline
\end{tabular}

Notes: The table represents a selection of discussed topics and is not intended to replace manuscript text. Some entries may expand on presented text in the specific section but reflect topics discussed throughout the manuscript. Presented topics are not intended to be exhaustive of all potentially useful research areas where considering the functional role of pain may improve research.

example, it is reasonable to assume that repetitive strain injuries ${ }^{14,15}$ may not heal fully if the precipitating activities are ongoing, and stress fractures ${ }^{16}$ or injured ligaments ${ }^{17}$ may take longer than 3 months to fully heal or for normal activity to resume.

Second, even when the duration-based demarcation does identify pain resulting from some pathology, not all conditions reflect pathology in the pain system itself (Figure 2C). Instead, some may still reflect functional pain brought on by injury or dysfunction in other bodily systems. For example, rheumatoid arthritis (RA) is a chronic inflammatory disease $^{18}$ whose symptoms include pain but its primary dysfunction is not in pain perception. Instead, the pain results from inflammation. Given the chronic nature of the condition, it would be expected that pain would also persist. The neuroplastic changes that accompany the chronic inflammation may appear as a dysfunction of the pain system, but without the ongoing RA, it would not exist. In this case, pain is a functional response to dysfunctional inflammation. Although distressing, the pain itself is not the pathology.

The International Classification of Diseases (ICD-11) begins to confront the distinction between functional pain and pathological pain via the introduction of separate diagnostic categories: chronic primary pain and chronic secondary pain 


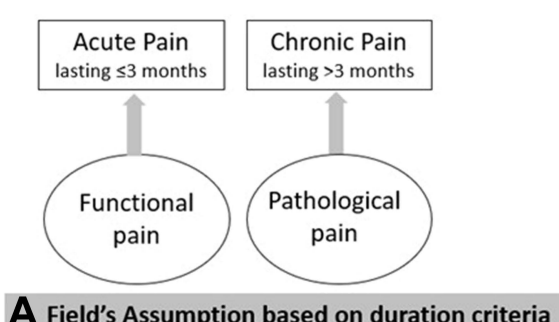

A Field's Assumption based on duration criteria

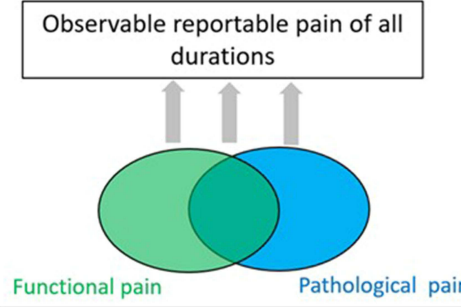

B Underlying constructs of pain (proposed)

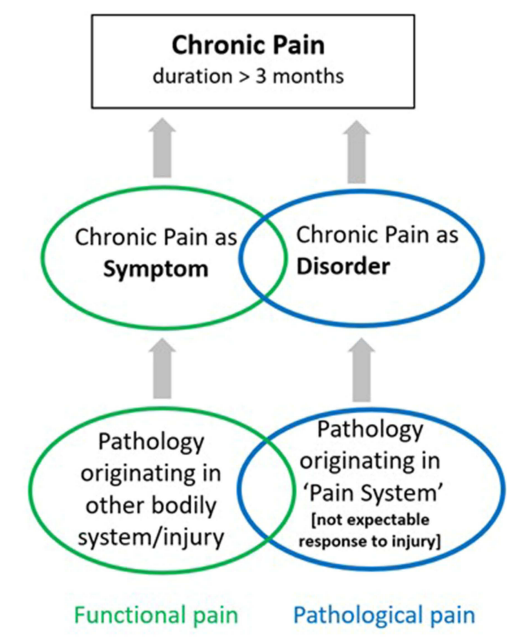

Chronic pain: duration criteria vs. intended latent constructs (as proposed)

Figure 2 Observable pain and the underlying constructs of interest. (A) Represents the predominant assumption in the literature regarding pain diagnostic categories based on duration criteria (ie, 3 months duration). (B) Illustrates the proposed concept that the observed pain regardless of duration may be due to functional pain, pathological pain, or a mixture of both since the ability to feel pain as functional pain within a biopsychosocial framework is present in all individuals even when pathological pain is present; thus, ratings of pain may capture this mix. (C) Reframes this for chronic pain as pain of >3-month duration to illustrate the potential misclassification issue presented by the duration criteria. The origin of the pathology or "internal-dysfunction" determines how to conceptualize the "disorder". That is, whether the condition represents pain as a symptom of another disorder or injury, or instead represents a disorder of the "pain system" itself. Again, overlaps highlight the challenge of isolating pathological from functional pain based on pain reports particularly given limits in the understanding of functional pain.

Notes: Rectangles represent observable/reportable pain. Ovals represent the intended latent constructs. The figure is not intended to replace the nuance in text or to fully capture complexity of pain or the challenge of classifying pain of unknown origin including neuropathic pain. "Pain system"is intended as a short cut to the nervous system processes responsible for the experience of pain, much of which is still to be understood. "Internal-dysfunction" refers to the Wakefield harmful-dysfunction analysis of disorder. ${ }^{88}$

(Table 1). ${ }^{19}$ Chronic primary pain "applies to chronic pain syndromes that are best conceived as health conditions in their own right". ${ }^{19}$ Essentially, these are conditions presumed to reflect pathological pain. Although the driving mechanisms are not well understood, the assumption has been generally described as "neural mechanisms gone awry" rather than merely a symptom of another condition. Examples of these include fibromyalgia, some presentations of complex regional pain syndrome (CRPS), and other musculoskeletal syndromes of unexplained pain, such as conditions where initiation may have been functional (due to insult that then resolved), but pain became pathological. Chronic secondary pain, on the other hand, encompasses conditions for which pain is a distressing symptom of a systemic or other disorder in another bodily system (see Table 1). This would reflect the functional role of pain of alerting to actual or potential tissue damage to promote healing and decrease further insult as in arthritis.

\section{Importance of Construct Validity of Research Targets-Functional vs Pathological Pain}

The distinction between functional and pathological pain is important for valid research, and sound clinical and public health practice. Functional pain alerts us to other health problems such as injury or systemic illness like RA. This reflects a healthy "pain system" as pain is serving its functional purpose. Even if it persists, it does so because the primary cause persists. Conversely, pathological pain indicates the pain system is not working as it should. For example, fibromyalgia or some presentations of complex regional pain syndrome are conditions where a functional cause for the pain is not

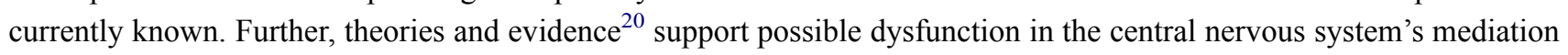
of the pain response, where it is triggered or heightened without cause. ${ }^{2,6}$ Pain may be treated regardless of the cause, but the best treatment approach for functional pain should consider the primary cause (injury, systemic illness, or pathogenic process), whereas pathological pain requires focus on the pain system itself.

If the target of intervention or research is misspecified (ie, presumed to be pathological pain) when studying healthy pain systems, dysfunction may be introduced. For example, there has been much promise and controversy over use of 
anti-nerve growth factor antibodies (anti-NGFs) as treatment for pain in osteoarthritis (OA) because of adverse events during clinical trials associated with more rapid joint degradation. ${ }^{21} \mathrm{OA}$ is a disease of the joint and thus pain is a result of deteriorating joint health, ${ }^{22}$ ie, pain is a symptom, not itself the disorder. Although drug trials resumed showing the efficacy at lower doses as equivalent while presenting fewer adverse events, ${ }^{23,24}$ this is an example of how focusing on pain as pathological, even when there is an alternate primary condition, may contribute to overlooking or worse, disregarding the primary pathology. In this case, joint health was the primary problem leading to pain, but the intervention targeted primarily reduction in pain, which itself may have led to unintended consequences for joint health.

Neuropathic pain may represent either functional or pathological pain. By definition, neuropathic pain is "[p]ain caused by a lesion or disease of the somatosensory nervous system", ${ }^{25}$ and thus can appear as the clear example of pathological pain since the dysfunction is in pain processing. However, when keeping the functional role of pain generally in mind, neuropathic pain is a more challenging construct. In some cases, it may reflect damage to tissue, including nerves, due to injury as in CRPS. Therefore, neuropathic pain could be conceptualized as functional pain, which alerts to injury and healing, rather than dysfunctional pain, albeit with unique sensory characteristics compared to non-neuropathic pain. On the other hand, neuropathic pain that has persisted past fully healed tissues or when no injury is present may be considered a primary dysfunction of the somatosensory system (eg, some presentations of CRPS) or at times, both functional and dysfunctional classifications need consideration. Often, the proportion of pain to initial injury is cited as evidence of pathological pain as in CRPS. ${ }^{26}$ However, because of known variability in the pain experience and how little is really understood about functional pain, the veracity of this is questionable. Although neuropathic pain as functional pain is not a dominant perspective, it is consistent with the ICD-11's classification of neuropathic pain as "secondary chronic pain" rather than the "primary chronic pain" designation except in some cases of CRPS reflecting similar logic. ${ }^{19}$

Misclassification of pain types may pose a significant challenge to the validity of etiologic studies. Pain disorders occur in bodies where the healthy potential for functional pain is ongoing. Therefore, there are significant challenges to measuring pain based on self-report ${ }^{27}$ including the fact that pain reports associated with pain disorders are often a mix of pain types reflecting functional and/or pathological pain. To ensure valid results, studies on a given construct need to measure that construct well, whether functional or pathological pain. Otherwise, misclassification of pain disorders or of pain outcomes (eg, ratings of pain intensity or severity, or functional outcomes due to pathological pain) as pathological when they reflect functional pain may bias study results either by introducing statistical noise leading to no effect when one exists (ie, type II error), or by mistaking effects resulting from measured functional pain as reflecting pathology in pain perception or processing. Pain research is plagued with inconsistent findings and/or lack of reproducibility, which may reflect, in part, this misspecification of pain target. Therefore, as is expanded on below, improving our ability to recognize pain as functional is important for both valid and reliable research, and by extension, safe and effective therapies.

\section{Key Consequences of Ignoring the Functional Role of Pain}

If the ability to experience pain when presented with noxious stimuli represents a healthy pain system, it follows that ignoring this function may lead to unintended consequences for health and well-being. Evidence of some of these potential unintended consequences are described below.

\section{The Opioid Crisis}

One well-documented example of an unintended consequence of the war on pain is the opioid crisis. ${ }^{28,29}$ Its causes are still being debated, but what is clear is the role of opioid medication, presumably initially for pain treatment, as a necessary factor. Although many other factors including bad actors in the pharmaceutical and healthcare industries, poverty and, in part, the prevalence of pain itself likely contributed to the crisis, its emergence may be partially the unintended consequence of the fight against pain. ${ }^{29,30}$ Specifically, calls were made to reframe and accept pain as a disorder that demands pharmacological treatment like any other disorder, to problematize pain as unnecessary and to define treatment that does not fully eliminate pain as inadequate pain management. It seems reasonable to assume that these efforts may have contributed to the epidemic, at least by unwittingly providing rationale for bad actors to widely 
promote opioid use. ${ }^{29,30}$ Moreover, because it appears that the body self-regulates and chronic use of opioids induces hyperalgesia, ${ }^{31}$ the cure may have become part of the problem. The results have been catastrophic. From 1999 to 2018 , nearly 450,000 people died in the United States from an overdose involving opioids (prescription or illicit). Countless others survive with debilitating addiction and communities have suffered, ${ }^{32}$ not to mention the significant setback and increased stigma that this presents for appropriate use of opioids and all medications for chronic pain treatment.

\section{Drug Side-Effects and Risk of Excessive Analgesia}

Opioid addiction is not the only potential pharmacologic unintended consequence to be considered. Drugs approved and effective for pain relief do pose risks. The potential adverse events associated with non-steroidal anti-inflammatory drugs (NSAIDs), for example, have been widely reported. ${ }^{33,34}$ Specifically, use of NSAIDs has been associated with increased risk of gastrointestinal (GI) bleeding, myocardial infarction, and stroke. ${ }^{33,34}$

Researchers have also begun to examine the potential ethical and unintended consequences of profoundly effective analgesics. ${ }^{35}$ Clark explains that, in addition to potential use or overuse, misuse and diversion, these medications may have unintended consequences for disease progression if they impact our "protective 'good pain' perception". ${ }^{35}$ This may manifest, for example, in failure to alter gait to protect joint health ${ }^{36}$ or as increased risk of injury due to reduced pain sensitivity. ${ }^{35}$ As in the anti-NGFs and OA example described above, failure to consider the role in health promotion of the targets of pharmacological interventions for pain, by not considering the impact on the functional role of pain, can have serious health consequences.

\section{Interfering with How Pain May Improve or Save Lives}

As described above, functional pain may manifest and confer benefits to the individual in ways that may not be clear, but that are important. For example, pain as a symptom of another illness can be a significant factor in early diagnosis and treatment. Pain is one of the top reasons why people seek emergency care. ${ }^{37-39}$ Therefore, from injuries to heart attacks ${ }^{40}$ to cancer, ${ }^{41}$ functional pain is associated with identification of these conditions and potentially the prevention of more serious outcomes. Because most treatments for a manifestation of pain do not target the specific pain, but have diffuse effects, analgesic effects may impact functional pain generally and the benefits of the functional role of pain in the above examples may be reduced. However, since there is little focus in the literature on the functional role of pain, studies neither explicitly explore the potential benefits of pain for health nor adequately investigate what may reduce these benefits. This knowledge would be critical for understanding the potential net impact of pain interventions so as not to unnecessarily interfere with the benefits that may be conferred by functional pain, or instead consider how to offset the impact of this interference as part of the intervention.

\section{Retarding Potential Research Gains on Chronic Pathological Pain}

The most critical and wide-reaching consequence of overlooking the functional role of pain is difficult to quantify — how it has stymied research progress specifically on chronic pathological pain. Because so little research explicitly considers the functional role of pain in the study of pathological pain, it is possible that the targets, study design and interpretation of much of the research to-date on chronic pain are negatively impacted. As a result, we may know less about pathological chronic pain than we may think. It is thus reasonable to assume that this contributes to inconsistent findings reported across studies (for one example, see studies on endogenous pain modulation in $\mathrm{TMDs}^{42,43}$ or fibromyalgia ${ }^{44}$ ), failure of novel drug therapies due to issues missed in translational research, ${ }^{45,46}$ and the continued high prevalence of pain conditions ${ }^{47}$ suggesting failure of research to address the population burden of pain. The misclassification of research targets as described above is hypothesized as a key contributor and delineated further in future sections on recommendations.

\section{Focusing Only on Pain as Pathology is an Inadequate Public Health Approach to Pain}

Finally, failure to consider the functional role of pain impedes the public health agenda on pain. At the moment the public health approach is largely focused on addressing the opioid crisis, specifically treating and preventing addiction, ${ }^{48}$ or on pain as pathology. ${ }^{49,50}$ However, most acute pain is considered to be functional pain, ${ }^{2,51,52}$ and perhaps many presentations of chronic pain may also reflect functional pain rather than pain as pathology. For example, chronic pain rates 
across countries estimate arthritis and low back pain as the top two chronic pain conditions. ${ }^{53}$ The pain associated with these conditions may to a great extent also be characterized as functional pain (or chronic secondary pain via ICD- $11^{19}$ ). Yet, public health approaches to pain focus almost exclusively on framing pain as pathology and, as noted above, this research is limited by misclassification of pain targets. Epidemiologic studies on pain often combine potential functional and pathological pain conditions in assessment of prevalence because they use a duration-based definition of chronic pain and do not consider the distinction (functional vs pathological pain) in interpretations (eg, $\mathrm{se}^{54-56}$ ). This failure makes it difficult to ascertain the relative contribution of each to pain as a population health problem.

Consequently, focus on pain as pathology may at times lead to poor intervention planning and resource allocation. If a condition is painful but not primarily a result of pathological pain processing, perhaps research dollars are better spent on understanding the primary pathology causing the pain rather than on studying pain from a pathological frame. Or, for the reasons outlined in this paper, research may yield clearer results if the potential functional role of pain is better considered as part of the implicated pain processes.

Pain is unique among public health problems. It is a largely normal part of the human experience, but even normal manifestations can be so devastating to the body and psyche that they simply cannot be ignored. Assuming pain, especially non-acute pain, is always pathological because of these aversive qualities may be more damaging than is appreciated because of the potential unintended consequences of erroneously transferring attention from the potential external cause of pain to presumed individual pain pathology. As a result, limits to the evidence-base and public health framing fail to advance a true public health approach to pain and health equity. They confound functional and pathological pain targets, which may require different therapeutic approaches to address pain as symptom (normal pain) vs pain as disorder (pathological pain) and for the gray areas in between. Having a broader more naturalistic view of the pain problem by re-centering research on the functional role of pain may help identify new non-pharmacological public health approaches to pain that also promote health equity. This includes exploring how to understand and address the noxious stimuli in our natural, social, home and occupational environments that initiate and maintain pain states, while preserving the benefits for health and well-being of the ability to feel pain.

\section{Recommendations for Anchoring Research on the Functional Role of Pain}

The above are thorny and not well-understood nuances that separate functional pain from pathological pain. Specifically, the fact that the presence of pain often presents without clear origin makes it difficult to identify if it is pathological or functional in nature. Research that is grounded on the theoretical understanding of the functional role of pain will be critical in this endeavor particularly for hypothesis development, operationalization of constructs and interpretation of research. Below are a few suggestions on specific research areas that can benefit from reframing the ability to feel pain as a good thing, including research that can advance our knowledge of the functional role of pain (Table 2).

\section{Evolutionary Understanding of Pain}

Many chronic pain presentations and papers begin with implicit acknowledgment of the evolutionary origins of pain and the importance of functional pain for survival - usually termed "good pain" or acute pain (see, eg, ${ }^{2,6}$ ). However, despite the centrality of evolutionary theory in the biological sciences, little if any research on the evolutionary origins of pain is cited to support these assertions. This is a significant gap in the scholarship on pain because "[o]ur understanding of the biology of pain is limited by our ignorance about its evolution". ${ }^{12}$

Researchers have recently alerted us to this gap ${ }^{12}$ and highlighted that evolutionary inquiry across fields can add to our understanding of nociceptive, psychological and social processes related to pain across species, including humans. Conclusions are premature, but research is nonetheless promising as it demonstrates how approaching research comparatively across species may help reveal functional characteristics of pain and yield a broader evolutionary perspective on adaptive benefit. ${ }^{57}$ For example, research studying differences and similarities in pain mechanisms across animals has led to questioning the default assumption that all chronic pain is maladaptive. ${ }^{7,12}$

Scholarship on evolutionary origins of pain produced by scholars with strong grounding in evolutionary theory and principles may facilitate better characterization of functional pain and by extension pathological pain. More specifically, 
"[u]nderstanding how evolution shaped the mechanisms and behaviours important for pain requires that the evolutionarily adaptive, neutral and maladaptive aspects of pain be identified". ${ }^{12}$ Evolutionary medicine has advanced theories of "chronic pain", but much of this is still theoretical. Improved understanding of how our bodies evolved to feel pain (ie, functional pain) and why we feel the range or manifestations of pain we do will help advance research on chronic pain and pathological assumptions, as well as move us from theory to evidence.

However, evolutionary perspectives on pain may fail or may promote ill-informed theories of chronic pain if not grounded on sound evolutionary scholarship. For example, common misconceptions about how natural selection operates are widespread. ${ }^{58} \mathrm{~A}$ true evolutionary perspective allows us to see that function is not about how useful pain is perceived to be by our modern-day standards, but rather, its benefits for survival in an evolutionary time frame. As such, research with a strong evolutionary theory base is needed to help characterize the functional role of pain and its manifestations.

\section{Developmental Perspectives on Pain Must Include the Study of Functional Pain}

Longitudinal research on pain in childhood offers a unique opportunity to study the natural history of functional pain. In the last decades, pain in infancy and childhood has finally gained recognition and due respect, ${ }^{59}$ leading to increased research on pain in childhood and its relation to adult pain experience, and many promising findings. ${ }^{60}$ However, this developmental work is also dominated by pathological pain; it is largely limited to how acute pain or stressors in childhood increase risk of pain problems later in life ${ }^{96,61}$ or how pediatric pain symptoms are a risk factor for adult chronic pain. ${ }^{62,63}$ Little if any research exists on understanding functional pain from a developmental perspective.

Research on deprivation in early life and its impact on neurologic development demonstrates that if deprived of "the types and amount of stimulation the brain needs to organize its pathways, then the brain may suffer" ${ }^{64}$ By extension, could this mean that exposure to pain inducing stimuli is necessary in some forms in order to develop a healthy pain system, one capable of functional pain? Given neuroplasticity's role in pain perception and processing, early life interventions may impact health of the pain system over the lifespan beyond simply increasing risk of adult chronic pain. For example, what may be excessive analgesia in childhood and what is its impact on the still developing somatosensory system? What are the range of common pain experiences in childhood and how are these related to healthy somatosensory system development? Other than congenitally driven disorders or diabetic neuropathy, is there a phenomenon of acquired insensitivity to pain and what are its risk factors? For example, we know pain sensitivity may change with age but little else is known. ${ }^{65}$ Given that research tends not to examine functional pain, it is hard to know the health consequences of its potential impairment through insult, medication or degeneration. As a result, research on pediatric pain and developmental research on pain may benefit from more directly considering the functional role of pain.

\section{Understanding the Functional Role of Pain Requires Research on Evidence of the Benefits of Pain}

As noted above, almost all research on pain is on its negative consequences for health and well-being. However, as pain is crucial for health and well-being, it follows that there must be some evidence of this and some benefit to better understanding it for public health and clinical practice. Research on pain should address questions in this area as well. For example, how much of the burden of pain is functional pain? Even research that is cited above as inadvertently providing evidence of the beneficial role of pain for improved health outcomes does not itself actively address that question. Moreover, what are the health-related benefits of pain? These questions and those in the previous section are just some of the relevant research questions not currently examined. Essentially, research must also try to understand the ways in which pain is beneficial for health and well-being to help identify where and how to leverage this benefit and identify where medicating or ignoring pain as a symptom may have negative impacts on health. 


\section{Consideration of Systems Science Approaches}

The complexity of pain is widely recognized and often cited as explanation for inconclusive or conflicting research findings. However, it is not pain that we seek to understand so much as the systems that give rise to it. Pain's complexity lies in the multiple bodily systems that drive diverse processes that bring about pain, the external environments to which these systems adapt and respond, and in the fact that functional processes are ongoing even while dysfunctions or pathologies emerge. Essentially, "[a] human being is a complex adaptive system coping with a social and physical environment but possessing nested subsystems", ${ }^{52}$ hence the importance of the biopsychosocial model for pain. ${ }^{3,4}$

Systems thinking, systems science, or systems approaches include a range of emerging theoretical and statistical methodologies ${ }^{66}$ used in the study of complex adaptive systems. Tools such as agent-based modeling, network analysis, system dynamics modeling, causal-loop or stock and flow diagrams are and can be used to study complex adaptive systems $^{66}$ in preclinical, clinical and public health research on pain. For example for the study of neural circuits, "[s] ystems neuroscience aims to understand how complex interactions between networks of neurons give rise to perception and behavior". ${ }^{67}$ Despite their potential utility for the study of pain generally few such examples of explicit use of systems approaches in the study of pain are found (eg theoretical attempts at understanding the nature of chronic pain $^{52,68,69}$ or within the healthcare context ${ }^{68}$ ). However, consideration of systems science approaches that are conceptually grounded ${ }^{70}$ may help to integrate research areas, advance whole-person-centered research and better address the challenges of studying pain to yield results. This can provide a common language based on systems terminology and approach to complexity (ie, dynamics and adaptation) across fields to help generate hypotheses about a theorized component or components of the system from cellular processes to societal factors, help interpretation and integration of evidence within a biopsychosocial framework, and provide novel statistical testing of hypotheses while considering complexity and interconnection across bodily systems and the external environment. These tools and theory base may be helpful in developing and evaluating multimodal therapies and will be particularly important as we rely more on big data, combined data sources and machine learning.

\section{Reducing What Gets Lost in Translation}

Given the rapid increase in research output globally ${ }^{71}$ and advances in technology, genetics and neuroscience, navigating existing knowledge to identify consistencies and decide on research priorities is difficult and susceptible to error. It is therefore critical that the functional role of pain be central to the translational research endeavor to reduce misclassification of constructs limiting advancements.

In particular, the models of pain used in research should be appropriate for the given research questions and should consider whether they reflect functional and/or pathological pain. The strengths and limitations of animal models of pain have been debated, ${ }^{51,72-75}$ but these debates show that animal research has been critical in helping uncover what we know about the neurobiology of pain. However, although efforts are made to model behavioral, emotional and psychological aspects of the pain experience, animal models largely rely on a construct that is only a partial representation of pain ${ }^{46}$-nociception, and all of them rely on some noxious insult whether mechanical, chemical or surgical. Advances have been made which include non-inflammatory pain models of muscle pain. ${ }^{73,76}$ However, these models are also predicated on noxious stimulation of the muscle tissues bringing into question their interpretation as a model for unexplained pathological pain. Meaning, since there is introduction of a noxious stimulus, this may be, by definition, inducing functional pain rather than the intended pathological pain. Therefore, reconsidering the functional role of pain may help to clarify what the models represent, how to improve them or the experiments that employ them, and/or promote better interpretation to bridge gaps where models are limited.

Another critical validity issue is that clinical and research constructs are often discordant or misaligned. Strict concordance may not be the answer, but this fact needs to be more actively engaged in research interpretation, again with consideration of the role of functional pain. For example, fibromyalgia diagnosed in clinical settings often looks very different than fibromyalgia that is the focus of research. Although the same term is used across settings, only about $25-50 \%$ of those clinically diagnosed with fibromyalgia meet the diagnostic criteria. ${ }^{77,78}$ Differences in one study were attributed to the clinical diagnosis being "disproportionally dependent on demographic and social factors rather than the symptoms 
themselves" ${ }^{77}$ These significant differences make it difficult to interpret conclusions reached from the collective etiologic "evidence" since evidence is accumulated on different constructs, perhaps confusing functional and pathological pain. This disconnect stymies progress and insidiously persists because it is often left unexamined in the research endeavor. Many reasons may drive these differences and they should be addressed, like the need for criteria to determine who receives insurance reimbursements and social service benefits. ${ }^{79,80}$ However, science should be determined by sound scientific theory, methods and evidence. Even when differences in use of the same term must be accepted, translational scholarship should do better at bridging the gap. We cannot define disorders solely by social convention (see next section). The role of pathological and functional processes needs to be at its center in order to avoid unintended consequences.

Interpreting and identifying implications of chronic pain research are also difficult in part because some pain processes are likely common in both functional and pathological pain, and similar language is used when studying their mechanisms. For example, although a range of central and peripheral mechanisms may be involved in both functional pain and fibromyalgia, ${ }^{20}$ the term central sensitization has been used to describe the prevailing theory of what is driving dysfunction in fibromyalgia, many other pain conditions and their co-occurrence. ${ }^{81}$ However, central sensitization is not by definition pathological as it is also observed in healthy controls. ${ }^{82}$ It is part of the body's adaptive mechanisms reacting to noxious stimuli. Confusion then ensues when similar terms are used to define both normal and pathological processes without adequate qualifications. Translational research with an evolutionary grounding can aid these advances.

Relatedly, limitations to inferences about cause and effect are also often overlooked across animal and human subjects' research on the mechanisms of pain. Since pain is induced by noxious stimuli, much of basic science research is, inadvertently, on functional pain which limits translation to understanding pathological pain. This is particularly true when hypotheses are confirmed in animal research where direct manipulation can be observed (ie, cutting a specific nerve and observing the impact from the injury to the brain, etc.) and then translated to human studies where manipulation is limited, and the brain and social structures are more complex. The experience of pain (and its precipitating cause) normally brings with it a multitude of peripheral and central nervous system changes that reflect the experience of pain, including those related to sickness behavior as part of the paradigm of defense mechanisms. ${ }^{52,83}$ This is part of what is observed when comparing individuals suffering with pain to pain-free controls. As with the example of central sensitization noted above, even with the most advanced imaging, quantitative sensory testing or invasive technologies to study neurobiological mechanisms, differentiating these markers of pain from evidence of what drives the pain is difficult without creative study design and sound theoretical grounding. However, this is seldom adequately considered, often because when pain is presumed to be pathological, all differences between cases and pain-free controls are interpreted through this lens. It is not considered that the observed processes reflect function rather than pathology or more simply, that they are the potential result of the pain experience rather than its cause.

Finally, where gaps in knowledge remain, translational conceptual and theoretical scholarship needs to invest in interpreting what is known in order to determine next steps in bridging these gaps. Melzack and Casey wrote "[t]heories of pain, like all scientific theories, evolve as result of the accumulation of new facts as well as leaps of the imagination". ${ }^{6,84}$ Translational research helps us make sense of the accumulation of knowledge, but translational scholarship needs more imagination. A decade ago, a commentary calling for renewed investment in basic science noted that "[t]ranslators need something to translate". ${ }^{85}$ This is true. It is also true that immense amount of knowledge across fields and levels of organization also need formidable translators. Researchers conducting primary research from bench to bedside or from bedside to public health, etc are only part of the solution. One major criticism has been that much of the accumulated evidence is not promptly or seldom translated into practice. ${ }^{86}$ Therefore, researchers and scholars who can interpret and communicate the scholarship gained across research to inform practice and research at all levels are needed. Since pain's aversive qualities make it so easy to forget its paramount functional role, these translation scholars can help ensure that language is both nuanced and consistent across fields to move us forward, without forgetting the functional role of pain.

\section{Needed Conceptual Grounding for Chronic Pain as "Disorder”}

Discussion of the above research areas illustrates that pain as disorder or disease needs more conceptual grounding. Because the term "disorder" is commonly used to differentiate pain as symptom from pain as disorder, ${ }^{19,87}$ it will be the 
term used here. Simply, "disorder" is used to identify something as not normal, an extreme manifestation causing harm to the individual, with the assumption of it resulting from something not working as it should in the body ${ }^{88}$ But here in lies the problem; pain is often a result of the body working exactly as it should - ie, functional pain that is potentially beneficial to health and well-being.

One conceptual framework that influenced the present work is the harmful-dysfunction analysis of disorder ${ }^{88}$ (Table 1) which acknowledges, as is the predominant view, that to be a disorder the condition must negatively impact the individual within a socio-historical context -the harm criterion. However, it also posits that harm is not enough. To meet criteria for disorder, the condition must result from the presence of an internal-dysfunction, ie, something not working as it should in the body based on its evolutionary function (the internal-dysfunction criterion). ${ }^{88}$ Both criteria must be met for the phenomenon to be considered a disorder. This framework helps to elucidate how not all persistent pain can or should be classified as disorders of pain (or chronic primary pain) because an internal-dysfunction in somatosensory functions and associated processes that bring about pain is not satisfied. In such cases, pain is a normal response to noxious stimuli, indicating that pain alerts to illness outside the pain system rather than a disorder of this system itself (Figure 2C).

This or other disorder frameworks can help conceptually ground our constructs and ensure we are focusing on the same or intended targets across research modalities - specifically, whether it is pain as disorder or pain as a symptom of another condition with its own internal-dysfunction outside of the pain system. Both targets are important, worthy of inquiry and interrelated, but need to be clearly differentiated and articulated in research and practice. Pain as a symptom puts the onus on treating the primary cause rather than the pain system itself, whereas disorder makes the pain itself the problem. When to utilize one approach over the other should be re-examined whilst still providing multimodal therapies for patients. But at the moment, the terms pain disorder and chronic pain are used for an array of presentations, conflating the notion of functional and pathological pain. Moreover, even when a specific dysfunction in pain processing may apply, having a specific pain disorder does not eliminate the need to consider the functional role of pain for the individual's well-being as that role is not limited to one manifestation of pain.

\section{Ethical Considerations and Epigenetics}

Pain in our modern lives is abundant. ${ }^{38,47,54}$ As described above, much of this pain can be arguably considered functional pain or pain of unclear origin where pathology is only theorized. As such, how to proceed is worth repeated ethical consideration in order to ameliorate all pain without interfering with the evolutionary function (ie, potential benefit) of the ability to feel pain. Because of the role of pain for mitigating environmental threat and improving chances of survival, in examining how to intervene on pain the broader physical, societal, work and interpersonal environments need consideration, not merely the body. Finding a solution for pain that is "normal" and not resulting from a dysfunctional nervous system requires that we engage challenging questions about how our societies are constructed to treat and care for our bodies, including the mechanics of our day-to-day lives and the values it represents. These considerations are what may best address why we are hurting, ie, as a result of noxious stimuli. It puts the onus on addressing the noxious stimuli as intended by the evolutionary origin of pain. This approach may also help significantly with pathological pain states, but those will also require different solutions that target dysfunction in the nervous system. As all pain hurts, bioethical scholarship in this arena requires consideration of the functional role of pain.

Early research on epigenetic influences (ie, changes in DNA methylation, histone modification, or chromatin remodeling without changes in the DNA sequence) on pain show how the environment may influence various painrelated mechanisms, such as inflammation and central sensitization. ${ }^{89-91}$ Broader research also shows that epigenetic mechanisms can have intergenerational impacts on health states either via hereditary or social transmission. ${ }^{92}$ Given epigenetic influences of the environment on pain physiology with potential long-term and intergenerational impacts, bioethics and pain researchers must consider the potential future consequences of current practice. For example, are there societal and medical norms and expectations around pain that are not adaptive, sustainable or not the best approach for promoting or maintaining overall health and well-being? Are there changes to how or where we live, work and play that may be more conducive to health and therefore less painful? 
The nature of pain is wedded to the environment to promote survival. This is further highlighted by the potential influence of epigenetics. As a result, as discussed above (disorder, evolution and public health sections), when deviation from evolutionary function arguments need to be accepted for defining pain as disorder, this cannot be done in haste, but with critical scientific and ethical consideration. Conclusions depend on the lens used for analysis and how designations of "pathological" and "functional" pain are negotiated. Given limited knowledge, this process of negotiating what is pathological will yield ethical dilemmas. The biggest danger in these gray areas is posed by science proceeding as if certainty exists. Therefore, recognizing the uncertainty by engaging with unknowns on the functional role of pain is the first defense against reification of inadequate constructs and their unintended consequences.

\section{Conclusions}

Research on chronic pain in recent decades has made strides in recognizing that many manifestations of chronic pain represent pain as disorder rather than just a symptom of other systemic illness or injury. ${ }^{19,26,87,93}$ However, much of this progress has failed to engage assumptions about what functional pain is, and its importance for and benefit to health. This paper describes some of the associated unintended consequences including the potential negative impact on research and public health efforts on pain. It is argued that at the core is the insidious misclassification of functional and pathological processes. Therefore, explicit consideration and research on functional pain is recommended. Specific areas of research, some already represented in pain research - eg, translational research on pain - are discussed. Other areas less represented in pain research - ie, evolutionary theory-based studies, or new areas like investigations of the possible ways the ability to feel pain improves health outcomes - have been recommended.

The fundamental assumption is that because the ability to feel pain is also important for health promotion, understanding and repeatedly considering the functional role of pain in chronic pain research will improve the quality of research and the ability of research to promote health. Specifically, it will directly address the issue at the core of possible misclassification in chronic pain - whether the pain reflects functional or pathological phenomena. This can only be done by improving our understanding of what functional pain is and its relation to duration of pain to better inform the use of duration-based criteria for chronic pain conditions. Moreover, understanding of functional pain will also advance conceptualization of dysfunction in the pain system versus dysfunction elsewhere in the body to reduce unintended consequences associated with this misclassification.

Understandably, when faced with the suffering of chronic pain, it is difficult to remember that there is any benefit to the ability to feel pain, but this must remain at the forefront as it is not the isolated pain we treat, but the whole person. A person's overall health and well-being relies on functional somatosensory and related systems of which the ability to feel pain, given a noxious stimulus, is an indicator of healthy function. Therefore, the ability to feel pain is important for well-being, although the amount of pain and its circumstances remains to be clarified. However, to establish these parameters in the best interest of healthy bodies, all pain cannot be considered bad and to be eliminated. The simple truth that the ability to feel pain is part of good health must be accepted in order to understand its potential consequences for research, patient care, and public health in the endeavor to reduce suffering.

\section{Acknowledgments}

The author would like to thank Drs Karen Raphael, Sharon Schwartz and Dane Cook, as well as Lauren Murray for invaluable feedback on previous versions of this manuscript. This work was initially supported by the Robert Wood Johnson Foundation Health \& Society Scholars program and currently by the National Institutes of Health (5K01DE028292).

\section{Disclosure}

Dr Vivian Santiago reports a grant from NIH and postdoctoral support from the Robert Wood Johnson Foundation Health \& Society Scholars program, during the conduct of the study, and reports no conflicts of interest in this work. 


\section{References}

1. Nesse RM, Schulkin J. An evolutionary medicine perspective on pain and its disorders. Philos Trans R Soc Lond B Biol Sci. 2019;374 (1785):20190288. doi:10.1098/rstb.2019.0288

2. Woolf CJ. What is this thing called pain? J Clin Invest. 2010;120(11):3742-3744. doi:10.1172/JCI45178

3. Engel GL. The need for a new medical model: a challenge for biomedicine. Science. 1977;196(4286):129-136. doi:10.1126/science.847460

4. Gatchel RJ, Peng YB, Peters ML, Fuchs PN, Turk DC. The biopsychosocial approach to chronic pain: scientific advances and future directions. Psychol Bull. 2007;133(4):581-624. doi:10.1037/0033-2909.133.4.581

5. Raja SN, Carr DB, Cohen M, et al. The revised International Association for the Study of Pain definition of pain: concepts, challenges, and compromises. Pain. 2020;161(9):1976-1982. doi:10.1097/j.pain.0000000000001939

6. Melzack R, Katz J. Pain. Wiley Interdiscip Rev Cogn Sci. 2013;4(1):1-15. doi:10.1002/wcs.1201

7. Walters ET. Adaptive mechanisms driving maladaptive pain: how chronic ongoing activity in primary nociceptors can enhance evolutionary fitness after severe injury. Philos Trans R Soc Lond B Biol Sci. 2019;374(1785):20190277. doi:10.1098/rstb.2019.0277

8. Nagasako EM, Oaklander AL, Dworkin RH. Congenital insensitivity to pain: an update. Pain. 2003;101(3):213-219. doi:10.1016/S0304-3959(02) $00482-7$

9. Tossani E. The concept of mental pain. Psychother Psychosom. 2013;82(2):67-73. doi:10.1159/000343003

10. Meerwijk EL, Weiss SJ. Toward a unifying definition: response to 'the concept of mental pain'. Psychother Psychosom. 2014;83(1):62-63. doi: $10.1159 / 000348869$

11. Popkirov S, Hoeritzauer I, Colvin L, Carson AJ, Stone J. Complex regional pain syndrome and functional neurological disorders - time for reconciliation. J Neurol Neurosurg Psychiatry. 2019;90(5):608-614. doi:10.1136/jnnp-2018-318298

12. Walters ET, Williams AC. Evolution of mechanisms and behaviour important for pain. Philos Trans R Soc Lond B Biol Sci. 2019;374 (1785):20190275. doi:10.1098/rstb.2019.0275

13. Treede RD, Rief W, Barke A, et al. A classification of chronic pain for ICD-11. Pain. 2015;156(6):1003-1007. doi:10.1097/j. pain. 000000000000160

14. Yassi A. Repetitive strain injuries. Lancet. 1997;349(9056):943-947. doi:10.1016/S0140-6736(96)07221-2

15. van Tulder M, Malmivaara A, Koes B. Repetitive strain injury. Lancet. 2007;369(9575):1815-1822. doi:10.1016/S0140-6736(07)60820-4

16. Saxena A, Fullem B, Hannaford D. Results of treatment of 22 navicular stress fractures and a new proposed radiographic classification system. $J$ Foot Ankle Surg. 2000;39(2):96-103. doi:10.1016/S1067-2516(00)80033-2

17. Hubbard TJ, Hicks-Little CA. Ankle ligament healing after an acute ankle sprain: an evidence-based approach. J Athl Train. 2008;43(5):523-529. doi:10.4085/1062-6050-43.5.523

18. Aletaha D, Neogi T, Silman AJ, et al. 2010 Rheumatoid arthritis classification criteria: an American College of Rheumatology/European League Against Rheumatism collaborative initiative. Arthritis Rheum. 2010;62(9):2569-2581. doi:10.1002/art.27584

19. Treede RD, Rief W, Barke A, et al. Chronic pain as a symptom or a disease: the IASP classification of chronic pain for the international classification of diseases (ICD-11). Pain. 2019;160(1):19-27. doi:10.1097/j.pain.0000000000001384

20. Sluka KA, Clauw DJ. Neurobiology of fibromyalgia and chronic widespread pain. Neuroscience. 2016;338:114-129. doi:10.1016/j. neuroscience.2016.06.006

21. Hochberg MC. Serious joint-related adverse events in randomized controlled trials of anti-nerve growth factor monoclonal antibodies. Osteoarthritis Cartilage. 2015;23(Suppl 1):S18-21. doi:10.1016/j.joca.2014.10.005

22. The American College of Rheumatology. Osteoarthritis; 2021. Available from: https://www.rheumatology.org/I-Am-A/Patient-Caregiver/DiseasesConditions/Osteoarthritis. Accessed April 16, 2021.

23. Chen J, Li J, Li R, et al. Efficacy and safety of tanezumab on osteoarthritis knee and hip pains: a meta-analysis of randomized controlled trials. Pain Med. 2017;18(2):374-385. doi:10.1093/pm/pnw262

24. Miller RE, Malfait AM, Block JA. Current status of nerve growth factor antibodies for the treatment of osteoarthritis pain. Clin Exp Rheumatol. 2017;107(5):85-87.

25. IASP Terminology. Pain terms. International Association for the Study of Pain. Available from: https://www.iasp-pain.org/Education/Content.aspx? ItemNumber=1698. Accessed May 27, 2021.

26. Merskey H, Bogduk N, eds. Classification of Chronic Pain: Descriptions of Chronic Pain Syndromes and Definitions of Pain Terms. 2nd ed. Seattle: IASP Press; 1994.

27. Younger J, McCue R, Mackey S. Pain outcomes: a brief review of instruments and techniques. Curr Pain Headache Rep. 2009;13(1):39-43. doi:10.1007/s11916-009-0009-x

28. DeWeerdt S. Tracing the US opioid crisis to its roots. Nature. 2019;573(7773):S10-s12. doi:10.1038/d41586-019-02686-2

29. Rummans TA, Burton MC, Dawson NL. How good intentions contributed to bad outcomes: the opioid crisis. Mayo Clin Proc. 2018;93(3):344-350. doi:10.1016/j.mayocp.2017.12.020

30. Sullivan MD, Ballantyne JC. Must we reduce pain intensity to treat chronic pain? Pain. 2016;157(1):65-69. doi:10.1097/j.pain.0000000000000336

31. Yi P, Pryzbylkowski P. Opioid induced hyperalgesia. Pain Med. 2015;16(Suppl 1):S32-36. doi:10.1111/pme.12914

32. Opioid overdose: understanding the epidemic. Georgia: Centers for Disease Control and Prevention, National Center for Injury Prevention and Control; 2020. Available from: https://www.cdc.gov/drugoverdose/epidemic/index.html. Accessed November 1, 2020.

33. Davis A, Robson J. The dangers of NSAIDs: look both ways. Br J Gen Pract. 2016;66(645):172-173. doi:10.3399/bjgp16X684433

34. Sostres C, Gargallo CJ, Arroyo MT, Lanas A. Adverse effects of non-steroidal anti-inflammatory drugs (NSAIDs, aspirin and coxibs) on upper gastrointestinal tract. Best Pract Res Clin Gastroenterol. 2010;24(2):121-132. doi:10.1016/j.bpg.2009.11.005

35. Clark JD. The pitfalls of profoundly effective analgesic therapies. Clin J Pain. 2008;24(9):825-831. doi:10.1097/AJP.0b013e3181773b7f

36. Schnitzer TJ, Popovich JM, Andersson GBJ, Andriacchi TP. Effect of piroxicam on gait in patients with osteoarthritis of the knee. Arthritis Rheum. 1993;36(9):1207-1213. doi:10.1002/art.1780360905

37. Johnston CC, Gagnon AJ, Fullerton L, Common C, Ladores M, Forlini S. One-week survey of pain intensity on admission to and discharge from the emergency department: a pilot study. J Emerg Med. 1998;16(3):377-382. doi:10.1016/S0736-4679(98)00012-2 
38. Mura P, Serra E, Marinangeli F, et al. Prospective study on prevalence, intensity, type, and therapy of acute pain in a second-level urban emergency department. J Pain Res. 2017;10:2781-2788. doi:10.2147/JPR.S137992

39. Tanabe P, Buschmann M. A prospective study of ED pain management practices and the patient's perspective. J Emerg Nurs. $1999 ; 25(3)$ :171-177. doi:10.1016/S0099-1767(99)70200-X

40. Johnson BD, Shaw LJ, Pepine CJ, et al. Persistent chest pain predicts cardiovascular events in women without obstructive coronary artery disease: results from the NIH-NHLBI-sponsored Women's Ischaemia Syndrome Evaluation (WISE) study. Eur Heart J. 2006;27(12):1408-1415. doi:10.1093/eurheartj/eh1040

41. Hamilton W, Peters TJ, Bankhead C, Sharp D. Risk of ovarian cancer in women with symptoms in primary care: population based case-control study. BMJ. 2009;339:b2998. doi:10.1136/bmj.b2998

42. La Touche R, Paris-Alemany A, Hidalgo-Perez A, Lopez-de-uralde-villanueva I, Angulo-Diaz-Parreno S, Munoz-Garcia D. Evidence for central sensitization in patients with temporomandibular disorders: a systematic review and meta-analysis of observational studies. Pain Pract. 2018 ; 18 (3):388-409. doi:10.1111/papr.12604

43. Moana-Filho EJ, Herrero Babiloni A, Theis-Mahon NR. Endogenous pain modulation in chronic orofacial pain: a systematic review and meta-analysis. Pain. 2018;159(8):1441-1455. doi:10.1097/j.pain.0000000000001263

44. O’Brien AT, Deitos A, Triñanes Pego Y, Fregni F, Carrillo-de-la-peña MT. Defective endogenous pain modulation in fibromyalgia: a meta-analysis of temporal summation and conditioned pain modulation paradigms. J Pain. 2018;19(8):819-836. doi:10.1016/j.jpain.2018.01.010

45. Kissin I. The development of new analgesics over the past 50 years: a lack of real breakthrough drugs. Anesth Analg. $2010 ; 110(3): 780-789$. doi:10.1213/ANE.0b013e3181cde882

46. Mao J. Current challenges in translational pain research. Trends Pharmacol Sci. 2012;33(11):568-573. doi:10.1016/j.tips.2012.08.001

47. Nahin RL, Sayer B, Stussman BJ, Feinberg TM. Eighteen-year trends in the prevalence of, and health care use for, noncancer pain in the United States: data from the medical expenditure panel survey. J Pain. 2019;20(7):796-809. doi:10.1016/j.jpain.2019.01.003

48. The Helping to End Addiction Long-term (HEAL) initiative. Maryland: National Institutes of Health; 2019. Available from: https:/heal.nih.gov/. Accessed February 21, 2021.

49. Gatchel RJ, Reuben DB, Dagenais S, et al. Research agenda for the prevention of pain and its impact: report of the work group on the prevention of acute and chronic pain of the federal pain research strategy. J Pain. 2018;19(8):837-851. doi:10.1016/j.jpain.2018.02.015

50. Gereau RW, Sluka KA, Maixner W, et al. A pain research agenda for the 21st century. J Pain. 2014;15(12):1203-1214. doi:10.1016/j. jpain.2014.09.004

51. Burma NE, Leduc-Pessah H, Fan CY, Trang T. Animal models of chronic pain: advances and challenges for clinical translation. J Neurosci Res. 2017;95(6):1242-1256. doi:10.1002/jnr.23768

52. Chapman CR, Tuckett RP, Song CW. Pain and stress in a systems perspective: reciprocal neural, endocrine, and immune interactions. $J$ Pain. 2008;9(2):122-145. doi:10.1016/j.jpain.2007.09.006

53. Tsang A, Von Korff M, Lee S, et al. Common chronic pain conditions in developed and developing countries: gender and age differences and comorbidity with depression-anxiety disorders. J Pain. 2008;9(10):883-891. doi:10.1016/j.jpain.2008.05.005

54. Dahlhamer J, Lucas J, Zelaya C, et al. Prevalence of chronic pain and high-impact chronic pain among adults - United States, 2016. MMWR Morb Mortal Wkly Rep. 2018;67(36):1001-1006. doi:10.15585/mmwr.mm6736a2

55. Hardt J, Clemma J, Jack G, Ralf N, Dedra B. Prevalence of chronic pain in a representative sample in the United States. Pain Med. 2008;9 (7):803-812. doi:10.1111/j.1526-4637.2008.00425.x

56. Kennedy J, Roll JM, Schraudner T, Murphy S, McPherson S. Prevalence of persistent pain in the U.S. adult population: new data from the 2010 national health interview survey. J Pain. 2014;15(10):979-984. doi:10.1016/j.jpain.2014.05.009

57. Howard RB, Lopes LN, Lardie CR, Perez PP, Crook RJ. Early-life injury produces lifelong neural hyperexcitability, cognitive deficit and altered defensive behaviour in the squid Euprymna scolopes. Philos Trans R Soc Lond B Biol Sci. 2019;374(1785):20190281. doi:10.1098/rstb.2019.0281

58. Williams AC. What can evolutionary theory tell us about chronic pain? Pain. 2016;157(4):788-790. doi:10.1097/j.pain.0000000000000464

59. Rodkey EN, Pillai Riddell R. The infancy of infant pain research: the experimental origins of infant pain denial. J Pain. 2013;14(4):338-350. doi:10.1016/j.jpain.2012.12.017

60. Walco GA, Krane EJ, Schmader KE, Weiner DK. Applying a lifespan developmental perspective to chronic pain: pediatrics to geriatrics. $J$ Pain. 2016;17(9):T108-T117. doi:10.1016/j.jpain.2015.11.003

61. Hermann C, Hohmeister J, Demirakça S, Zohsel K, Flor H. Long-term alteration of pain sensitivity in school-aged children with early pain experiences. Pain. 2006;125(3):278-285. doi:10.1016/j.pain.2006.08.026

62. Jones GT, Silman AJ, Power C, Macfarlane GJ. Are common symptoms in childhood associated with chronic widespread body pain in adulthood?: results from the 1958 British birth cohort study. Arthritis Rheum. 2007;56(5):1669-1675. doi:10.1002/art.22587

63. Walker LS, Sherman AL, Bruehl S, Garber J, Smith CA. Functional abdominal pain patient subtypes in childhood predict functional gastrointestinal disorders with chronic pain and psychiatric comorbidities in adolescence and adulthood. Pain. 2012;153(9):1798-1806. doi:10.1016/j. pain.2012.03.026

64. Nelson CA, Bos K, Gunnar MR, Sonuga-Barke EJS. The neurobiological toll of early human deprivation. Monogr Soc Res Child Dev. 2011;76 (4):127-146. doi:10.1111/j.1540-5834.2011.00630.x

65. Lautenbacher S, Peters JH, Heesen M, Scheel J, Kunz M. Age changes in pain perception: a systematic-review and meta-analysis of age effects on pain and tolerance thresholds. Neurosci Biobehav Rev. 2017;75:104-113. doi:10.1016/j.neubiorev.2017.01.039

66. Peters DH. The application of systems thinking in health: why use systems thinking? Health Res Policy Syst. 2014;12(1):51. doi:10.1186/14784505-12-51

67. Callaway EM. A molecular and genetic arsenal for systems neuroscience. Trends Neurosci. 2005;28(4):196-201. doi:10.1016/j.tins.2005.01.007

68. Brown CA. Pain and complex adaptive system theory. In: Sturmberg JP, Martin CM, editors. Handbook of Systems and Complexity in Health. New York: Springer New York; 2013:397-421.

69. Chapman CR. Painful multi-symptom disorders: a systems perspective. In: Kruger L, Light AR, editors. Translational Pain Research: From Mouse to Man. Boca Raton, FL: CRC Press/Taylor \& Francis Llc.; 2010.

70. Ness RB, Koopman JS, Roberts MS. Causal system modeling in chronic disease epidemiology: a proposal. Ann Epidemiol. 2007;17(7):564-568. doi:10.1016/j.annepidem.2006.10.014 
71. Publications output: U.S. trends and international comparisons. Alexandria, VA: National Center for Science and Engineering Statistics; 2019. Available from: https://ncses.nsf.gov/pubs/nsb20206/. Accessed June 262021.

72. Abboud C, Duveau A, Bouali-Benazzouz R, et al. Animal models of pain: diversity and benefits. J Neurosci Methods. $2021 ; 348: 108997$. doi:10.1016/j.jneumeth.2020.108997

73. Gregory NS, Harris AL, Robinson CR, Dougherty PM, Fuchs PN, Sluka KA. An overview of animal models of pain: disease models and outcome measures. J Pain. 2013;14(11):1255-1269. doi:10.1016/j.jpain.2013.06.008

74. Mogil JS. Animal models of pain: progress and challenges. Nat Rev Neurosci. 2009;10(4):283-294. doi:10.1038/nrn2606

75. Mogil JS, Davis KD, Derbyshire SW. The necessity of animal models in pain research. Pain. 2010;151(1):12-17. doi:10.1016/j.pain.2010.07.015

76. Sluka KA, Kalra A, Moore SA. Unilateral intramuscular injections of acidic saline produce a bilateral, long-lasting hyperalgesia. Muscle Nerve. 2001;24(1):37-46. doi:10.1002/1097-4598(200101)24:1<37::AID-MUS4>3.0.CO;2-8

77. Walitt B, Katz RS, Bergman MJ, Wolfe F. Three-quarters of persons in the US population reporting a clinical diagnosis of fibromyalgia do not satisfy fibromyalgia criteria: the 2012 National Health Interview Survey. PLoS One. 2016;11(6):e0157235. doi:10.1371/journal.pone.0157235

78. Wolfe F, Schmukler J, Jamal S, et al. Diagnosis of fibromyalgia: disagreement between fibromyalgia criteria and clinician-based fibromyalgia diagnosis in a university clinic. Arthritis Care Res. 2019;71(3):343-351.

79. Wolfe F, Hauser W, Walitt BT, Katz RS, Rasker JJ, Russell AS. Fibromyalgia and physical trauma: the concepts we invent. J Rheumatol. 2014;41 (9):1737-1745. doi:10.3899/jrheum.140268

80. Wolfe F, Walitt BT, Katz RS, Häuser W. Social security work disability and its predictors in patients with fibromyalgia. Arthritis Care Res. 2014;66 (9):1354-1363. doi:10.1002/acr.22305

81. Yunus MB. Fibromyalgia and overlapping disorders: the unifying concept of central sensitivity syndromes. Semin Arthritis Rheum. 2007;36 (6):339-356. doi:10.1016/j.semarthrit.2006.12.009

82. Woolf CJ. Central sensitization: implications for the diagnosis and treatment of pain. Pain. 2011;152(3 Suppl):S2-S15. doi:10.1016/j. pain.2010.09.030

83. Shattuck EC, Muehlenbein MP. Human sickness behavior: ultimate and proximate explanations. Am J Phys Anthropol. 2015;157(1):1-18. doi:10.1002/ajpa.22698

84. Kuhn T. The Structure of Scientific Revolutions. Chicago: University of Chicago Press; 1970.

85. Fang FC, Casadevall A. Lost in translation-basic science in the era of translational research. Infect Immun. 2010;78(2):563-566. doi:10.1128/ IAI.01318-09

86. Grimshaw JM, Eccles MP, Lavis JN, Hill SJ, Squires JE. Knowledge translation of research findings. Implement Sci. 2012;7:50. doi:10.1186/17485908-7-50

87. Raffaeli W, Arnaudo E. Pain as a disease: an overview. J Pain Res. 2017;10:2003-2008. doi:10.2147/JPR.S138864

88. Wakefield JC. The concept of mental disorder. On the boundary between biological facts and social values. AmPsychol. 1992;47(3):373-388.

89. Buchheit T, Van de Ven T, Shaw A. Epigenetics and the transition from acute to chronic pain. Pain Med. 2012;13(11):1474-1490. doi:10.1111/ j.1526-4637.2012.01488.x

90. Denk F, McMahon Stephen B. Chronic pain: emerging evidence for the involvement of epigenetics. Neuron. 2012;73(3):435-444. doi:10.1016/j. neuron.2012.01.012

91. Polli A, Ickmans K, Godderis L, Nijs J. When environment meets genetics: a clinical review of the epigenetics of pain, psychological factors, and physical activity. Arch Phys Med Rehabil. 2019;100(6):1153-1161. doi:10.1016/j.apmr.2018.09.118

92. Mashoodh R, Champagne FA. Chapter 6 - paternal epigenetic inheritance. In: Tollefsbol TO, editor. Transgenerational Epigenetics. 2nd ed. Vol. 13. Academic Press; 2019:107-133.

93. Clauw DJ, Essex MN, Pitman V, Jones KD. Reframing chronic pain as a disease, not a symptom: rationale and implications for pain management. Postgrad Med. 2019;131:1-14.

94. Global year against acute pain, October 2010-October 2011. International Association for the Study of Pain; 2010 . Available from: https://s3. amazonaws.com/rdcms-iasp/files/production/public/Content/ContentFolders/GlobalYearAgainstPain2/AcutePainFactSheets/1-Problem.pdf. Accessed May 27, 2021.

95. Nicholas M, Vlaeyen JWS, Rief W, et al. The IASP classification of chronic pain for ICD-11: chronic primary pain. Pain. $2019 ; 160(1): 28-37$. doi:10.1097/j.pain.0000000000001390

96. Davis DA, Luecken LJ, Zautra AJ. Are reports of childhood abuse related to the experience of chronic pain in adulthood? A meta-analytic review of the literature. Clin J Pain. 2005;21(5):398-405. doi:10.1097/01.ajp.0000149795.08746.31

Journal of Pain Research

Dovepress

\section{Publish your work in this journal}

The Journal of Pain Research is an international, peer reviewed, open access, online journal that welcomes laboratory and clinical findings in the fields of pain research and the prevention and management of pain. Original research, reviews, symposium reports, hypothesis formation and commentaries are all considered for publication. The manuscript management system is completely online and includes a very quick and fair peer-review system, which is all easy to use. Visit http://www.dovepress.com/testimonials.php to read real quotes from published authors.

Submit your manuscript here: https://www.dovepress.com/journal-of-pain-research-journal 